\title{
RNA Interference by Cyanobacterial Feeding Demonstrates the SCSG1 Gene Is Essential for Ciliogenesis during Oral Apparatus Regeneration in Stentor
}

\author{
Wei Wei ${ }^{1,+}$, Chuanqi Jiang ${ }^{1,2,3,4,+}$, Xiaocui Chai ${ }^{1}$, Juyuan Zhang ${ }^{1}$, Cheng-Cai Zhang ${ }^{1}\left(\mathbb{D}\right.$, Wei Miao ${ }^{1,5,6}$ and \\ Jie Xiong ${ }^{1, *}$
}

check for

updates

Citation: Wei, W.; Jiang, C.; Chai, X.; Zhang, J.; Zhang, C.-C.; Miao, W.;

Xiong, J. RNA Interference by

Cyanobacterial Feeding

Demonstrates the SCSG1 Gene Is

Essential for Ciliogenesis during Oral Apparatus Regeneration in Stentor. Microorganisms 2021, 9, 176. https:// doi.org/10.3390/microorganisms 9010176

Received: 16 December 2020 Accepted: 13 January 2021

Published: 15 January 2021

Publisher's Note: MDPI stays neutral with regard to jurisdictional clai$\mathrm{ms}$ in published maps and institutional affiliations.

Copyright: $\odot 2021$ by the authors. Licensee MDPI, Basel, Switzerland. This article is an open access article distributed under the terms and conditions of the Creative Commons Attribution (CC BY) license (https:// creativecommons.org/licenses/by/ $4.0 /)$.
1 Key Laboratory of Aquatic Biodiversity and Conservation, Institute of Hydrobiology, Chinese Academy of Sciences, Wuhan 430072, China; weiwei10081009@163.com (W.W.); jiangchuanqi@ihb.ac.cn (C.J.); chaixiaocui@ihb.ac.cn (X.C.); zhangjuyuan@ihb.ac.cn (J.Z.); cczhang@ihb.ac.cn (C.-C.Z.); miaowei@ihb.ac.cn (W.M.)

2 Shenzhen Institute of Guangdong Ocean University, Shenzhen 518120, China

3 Guangdong Provincial Engineering Research Center for Aquatic Animal Health Assessment, Shenzhen 518120, China

4 Shenzhen Public Service Platform for Evaluation of Marine Economic Animal Seedings, Shenzhen 518120, China

5 CAS Center for Excellence in Animal Evolution and Genetics, Kunming 650223, China

6 State Key Laboratory of Freshwater Ecology and Biotechnology of China, Wuhan 430072, China

* Correspondence: xiongjie@ihb.ac.cn; Tel.: +86-27-68780209

+ These authors contributed equally to this work.

Abstract: In the giant ciliate Stentor coeruleus, oral apparatus (OA) regeneration is an experimentally tractable regeneration paradigm that occurs via a series of morphological steps. OA regeneration is thought to be driven by a complex regulatory system that orchestrates the temporal expression of conserved and specific genes. We previously identified a S. coeruleus-specific gene (named SCSG1) that was significantly upregulated during the ciliogenesis stages of OA regeneration, with an expression peak at the stage of the first OA cilia appearance. We established a novel RNA interference (RNAi) method through cyanobacteria Synechocystis sp. PCC6803 feeding in S. coeruleus. The expression of SCSG1 gene was significantly knocked down by using this method and induced abnormal ciliogenesis of OA regeneration in S. coeruleus, suggesting that SCSG1 is essential for OA regeneration in $S$. coeruleus. This novel RNAi method by cyanobacterial feeding has potential utility for studying other ciliates.

Keywords: ciliate; novel RNAi method; Synechocystis sp. PCC6803; oral apparatus regeneration

\section{Introduction}

The giant ciliated protozoan, Stentor coeruleus, is a tractable model for studying regeneration at the single-cell level. Regeneration of the oral apparatus (OA) and holdfast, and normal shape reconstitution have all been described in S. coeruleus [1]. Thereinto, OA regeneration is an attractive and tractable regeneration paradigm in S. coeruleus. The OA is the predominant structure on the anterior end of the cell. It consists of thousands of long cilia organized into membranelles that compose the membranellar band (MB) [2]. In S. coeruleus, OA shedding can be induced by short urea treatment [3]; after removal and washing, the cells can completely regenerate the $\mathrm{OA}$ and finally restore the feeding ability within $9 \mathrm{~h}$, progressing through a series of well-characterized morphological steps $[1,4,5]$. Single-cell transcriptome analysis revealed that the morphological steps in OA regeneration are driven by a complex regulatory system that includes centriole assembly, ciliogenesis, signaling, cell cycle regulation, transcription, and RNA binding in S. coeruleus [4]. Using proteomic identification, we identified $882 \mathrm{OA}$-associated proteins in extracts from the 
shedding OA of $S$. coeruleus; most were highly and continuously expressed in OA regeneration [5]. However, few studies so far have focused on the function of genes involved in OA regeneration.

In many non-model ciliates, RNAi is used to study gene function, and RNAi methodologies have been established for Paramecium [6], Euplotes [7], Oxytricha [8], and Stylonychia [9] species. Such RNAi studies have commonly used Escherichia coli HT115, an RNase Ш-deficient feeding strain containing the isopropyl $\beta$-D-1-thiogalactopyranoside (IPTG)inducible T7 polymerase, transformed with the L4440 double-T7-promoter feeding vector [10]. After inducing double-stranded RNA (dsRNA) expression from the L4440 plasmid, E. coli HT115 cells are fed to the ciliate to elicit RNAi till the appearance of phenotypes [6]. Using this method, RNAi against the kinase regulator Mob1 has been successfully induced in S. coeruleus [11]. However, the RNAi method based on E. coli HT115 must be induced to express dsRNA in the presence of the IPTG, and this method may not work in some ciliates (e.g., Vorticella [12]). Hence, a new RNAi method involving constitutive dsRNA expression without any induction is needed.

For the above reasons, we turned to the cyanobacterium Synechocystis sp. PCC6803 (hereafter, Synechocystis 6803). Synechocystis 6803 is a unicellular freshwater cyanobacterium that was initially isolated from a freshwater lake in 1968 [13], and has since become one of the most extensively studied cyanobacterial species. Synechocystis 6803 can be easily cultivated in either solid or liquid culture systems and in absence or presence of light. Its genome was fully sequenced in 1996 [14] and it can readily take up exogenous DNA via natural transformation, electroporation, ultrasonic transformation and conjugation [15]. Therefore, Synechocystis 6803 is considered a model organism that can be used for genetic engineering in cyanobacteria. Owing to its slow doubling time, it is more efficient to perform DNA cloning in a fast-growing host, such as E. coli strain DH10B [16,17], which carries the pRL443 conjugal plasmid and the pRL623 helper plasmid [18]. Generally, a shuttle vector with a broad host range and an effective gene promoter are required to create a stably replicating plasmid that will function in both E. coli and Synechocystis 6803. The RSF1010 vector [19] and the derivative, pSB2A [15], can successfully replicate in Synechocystis 6803. The constitutive $C$-phycocyanin $\beta$ promoter $\left(\mathrm{P}_{c p c B}\right)$, a slightly modified variant of the native $\mathrm{P}_{c p c}$ from Synechocystis 6803, has been successfully applied in different Synechocystis strains [20-22]. Particularly high production of heterologous proteins in cyanobacteria have been achieved using $\mathrm{P}_{c p c 560}$, a truncated version of $\mathrm{P}_{c p c B}$ [22]. Hence, the strong constitutive $\mathrm{P}_{c p c B}$ can control heterologous gene expression in Synechocystis 6803. Finally, Synechocystis 6803 can acquire exogenous DNA from E. coli via bacterial conjugation [23].

We established a novel RNAi method for the constitutive expression of exogenous gene dsRNA in Synechocystis 6803 and successfully applied this method to knock down a previous identified S. coeruleus-specific gene (named SCSG1), known to be associated with $\mathrm{OA}$ regeneration [5], and verified its function in ciliogenesis of OA regeneration.

\section{Materials and Methods}

\subsection{Cell Culture and Growth Conditions}

S. coeruleus (strain WHEL) [5] cells were grown at $20^{\circ} \mathrm{C}$ in the dark in Modified Stentor Medium (MSM) [11], supplemented with Chlorogonium elongatum as living prey. Wild-type (WT) and the transformed strains of Synechocystis 6803 were grown at $30^{\circ} \mathrm{C}$ in liquid or solid Blue-Green-11 (BG-11) medium at a light intensity of $40 \mu \mathrm{moL}$ photons $\mathrm{m}^{-2} \mathrm{~s}^{-1}$ in ambient air. Kanamycin $(\mathrm{Km})$ was added to BG-11 medium at a concentration of $25 \mu \mathrm{g} / \mathrm{mL}$ or $50 \mu \mathrm{g} / \mathrm{mL}$ when required. Cell growth was monitored by measuring the optical density at $580 \mathrm{~nm}\left(\mathrm{OD}_{580}\right)$ of the cultures on a UNIC 7200 spectrophotometer (UNIC, Shanghai, China). The E. coli DH10B strain carrying the pRL443 conjugal plasmid and the pRL623 helper plasmid was the host for all plasmids constructed in this study. E. coli cells were grown in Luria-Bertani (LB) medium at $37^{\circ} \mathrm{C}$ with continuous shaking. Carbenicillin 
(50 $\mu \mathrm{g} / \mathrm{mL})$, chloramphenicol $(25 \mu \mathrm{g} / \mathrm{mL})$ or $\mathrm{Km}(50 \mu \mathrm{g} / \mathrm{mL})$ was added to the LB medium when required for the propagation of plasmids in E. coli.

\subsection{RNAi Expression Vector Construction}

The pSCTGA vector, containing a Km resistance cassette with mobilization (Mob) genes, was constructed based on the plasmid RSF1010 [24], and can successfully replicate in Synechocystis 6803. The pSCTGA vector was modified for use as an RNAi expression vector in Synechocystis 6803. Firstly, the pSCTGA vector backbone (pSCTGA-backbone) containing the replication elements, Mob gene, and $\mathrm{Km}$ resistance gene was cloning using the primer pair, pSCTGA-backbone-F and pSCTGA-backbone-R (Table S1). The forward and reverse sequences of $\mathrm{P}_{c p c B}\left(\mathrm{FP}_{c p c B}\right.$ and $\left.\mathrm{RP}_{c p c B}\right)$ were $\mathrm{PCR}$ amplified from the WT Synechocystis 6803 genome using the primer pairs, $\mathrm{FP}_{c p c B}-\mathrm{F}+\mathrm{FP}_{c p c B}-\mathrm{R}$ and $\mathrm{RP}_{c p c B}-\mathrm{F}+$ $\mathrm{RP}_{c p c B}-\mathrm{R}$, respectively (Table S1). The multiple cloning site (MCS) was PCR amplified from L4440 vector [10] using the primer pair, MCS-F and MCS-R (Table S1). Next, the $\mathrm{FP}_{c p c B}, \mathrm{MCS}$ and $\mathrm{RP}_{c p c B}$ DNA fragments were jointed together to form a recombinant DNA fragment $\left(\mathrm{FP}_{c p c B}-\mathrm{MCS}-\mathrm{RP}_{c p c B}\right)$ using fusion $\mathrm{PCR}$ with the primer pairs, $\mathrm{FP}_{c p c B}-\mathrm{F}+\mathrm{MCS}-\mathrm{R}$ and $\mathrm{FP}_{c p c B}-\mathrm{F}+\mathrm{RP}_{c p c B}-\mathrm{R}$ (Table S1). Finally, the $\mathrm{FP}_{c p c B}-\mathrm{MCS}-\mathrm{RP} \mathrm{P}_{c p c B}$ DNA fragment was joined to the pSCTGA-backbone in a correct orientation via the one-step cloning method to form the pSCT3C RNAi expression vector.

\subsection{Plasmid Construction}

To clone Stentor gene sequences, homologs were identified by best-reciprocal BLAST between the S. coeruleus WHEL [5] transcriptome and the S. coeruleus WM001 genome [25]. Target gene sequences were obtained by PCR amplification from $S$. coeruleus WHEL genomic DNA. PCR fragments were digested with BglII and KpnI and then ligated into the pSCT3C vector, which had been linearized with the same restriction enzymes. The resulting plasmids were transfected into E. coli DH10B cells. Additional information about the RNAi constructs used in this study according to the method of Slabodnick et al. [11] is given in Table S2.

\subsection{Synechocystis 6803 Transformation and Identification}

Transformation was performed by the conjugal transfer method [23]. Briefly, Synechocystis 6803 cells were centrifuged from $14 \mathrm{~mL}$ of a logarithmic phase $\left(\mathrm{OD}_{580}=\sim 1\right)$ culture at 13,000 rpm for $2 \mathrm{~min}$. The pellet was resuspended in $1.4 \mathrm{~mL}$ fresh BG-11 medium. Aliquots $(2 \mathrm{~mL})$ of $E$. coli cells carrying various plasmids (including the empty pSCT3C plasmid) from logarithmic phase $\left(\mathrm{OD}_{600}=\sim 1\right)$ cultures were centrifuged under the same conditions. Cell pellets were resuspended in $200 \mu \mathrm{L}$ fresh BG-11 medium, mixed with $200 \mu \mathrm{L}$ Synechocystis 6803 cells, and incubated at $30{ }^{\circ} \mathrm{C}$ for $6 \mathrm{~h}$ at a light intensity of $40 \mu \mathrm{moL}$ photons $\mathrm{m}^{-2} \mathrm{~s}^{-1}$. Cultures were then spread onto BG-11 agar plates without antibiotics. After incubation for $24 \mathrm{~h}$ at $30^{\circ} \mathrm{C}$ under a light intensity of $40 \mu \mathrm{moL}$ photons $\mathrm{m}^{-2} \mathrm{~s}^{-1}, 25 \mu \mathrm{g} / \mathrm{mL} \mathrm{Km}$ was added and plates were incubated at $30{ }^{\circ} \mathrm{C}$ for approximately 2 weeks at a light intensity of $40 \mu \mathrm{moL}$ photons $\mathrm{m}^{-2} \mathrm{~s}^{-1}$ until colonies appeared. Single colonies were propagated on individual BG-11 agar plates containing $25 \mu \mathrm{g} / \mathrm{mL} \mathrm{Km}$ and inoculated into liquid BG-11 medium containing $50 \mu \mathrm{g} / \mathrm{mL} \mathrm{Km}$ for analysis. To determine the identity of cargo plasmids in transformed Synechocystis 6803, transformants were subjected to bacterial colony PCR and PCR products were analyzed by $1 \%$ agarose gel electrophoresis.

\subsection{Reverse Transcription-PCR Assay}

For each sample, total RNA was extracted from a $50 \mathrm{~mL}$ aliquot of transformed Synechocystis 6803 cultured at an OD $_{580}$ of $\sim 1$ using the TransZol Up Plus RNA kit (TransGen, Beijing, China), following the manufacturer's instructions. Contaminating was removed with RNase-free DNase (Qiagen, Dusseldorf, Germany). Reverse transcription was carried out using M-MLV Reverse Transcriptase Assay (Invitrogen, Carlsbad, CA, USA). The 
resulting cDNA molecules were PCR amplified using the primer pairs shown in Table S2. All reactions were performed on the Eppendorf PCR Mastercycler (Eppendorf, Hamburg, Germany). Each reaction was performed in a total volume of $50 \mu \mathrm{L}$, including $8 \mu \mathrm{L}$ cDNA, $2 \mu \mathrm{L} 10 \mu \mathrm{mol} / \mathrm{L}$ of each primer, and $38 \mu \mathrm{L} 1 \times$ BioReady ePfu Mix (BioFlux, Beijing, China). Amplification conditions were $94^{\circ} \mathrm{C}$ for $5 \mathrm{~min}$, followed by 29 cycles of $94{ }^{\circ} \mathrm{C}$ for $30 \mathrm{~s}, 60^{\circ} \mathrm{C}$ for $30 \mathrm{~s}$, and $72{ }^{\circ} \mathrm{C}$ for $1 \mathrm{~min}$, and a final extension at $72{ }^{\circ} \mathrm{C}$ for another $10 \mathrm{~min}$. Reverse transcription-PCR (RT-PCR) products were analyzed by $1 \%$ agarose gel electrophoresis.

\subsection{RNAi by Feeding with Synechocystis 6803}

RNAi was performed by transforming Synechocystis 6803 with each plasmid to allow for dsRNA expression of the target gene. Transformed Synechocystis 6803 cells were grown to early logarithmic phase $\left(\mathrm{OD}_{580}=\sim 0.4\right)$ and then fed to $S$. coeruleus cells that had been previously starved for 24-48 h. Every $30 \mathrm{~S}$. coeruleus cells were fed with enriched $5 \mathrm{~mL}$ Synechocystis 6803 cells $\left(\mathrm{OD}_{580}=\sim 0.4\right)$ carrying various plasmids every 3 days for a total of 10-14 days, respectively. Controls cells were fed with either WT Synechocystis 6803 or Synechocystis 6803 transformed with empty pSCT3C plasmid.

\subsection{Single-Cell RNA-Sequencing and Gene Expression Analysis}

Single cells were isolated and their transcriptomes were amplified using Smart-Seq2 (SMARTer Ultra Low RNA kit (Art. No. 634936, Clontech, Mountain View, CA, USA) for Illumina sequencing, with an insert size of about $350 \mathrm{bp}$. RNA libraries were constructed according to the manufacturer's protocols. Paired-end $(150 \mathrm{bp} \times 2)$ sequencing was performed for all the single-cell RNA libraries using an Illumina NovaSeq 6000 sequencer (Illumina, San Diego, CA, USA). Raw single-cell RNA-sequencing (RNA-seq) reads were filtered by fqtools plus (https://github.com/annoroad/fqtools_plus) to trim away the reads with adapters ( $>5 \mathrm{bp}$ adapter nucleotide) and high $\mathrm{N}$ ratio $(>5 \%)$. Additionally, the reads were filtered by the fastq quality filter FASTX-Toolkit (-q 20, -p 80) (http:/ /hannonlab. cshl.edu/fastx_toolkit/). Firstly, we de novo assembled a reference transcriptome by merging all RNA-seq datasets in this study using Trinity [26] with default parameters. The assembled transcript fragments served as reference transcriptome sequences. Filtered reads were mapped back to the reference transcriptome and the read count for each gene was obtained using the RSEM output integrated into Trinity [26] with default parameters. We chose the number of fragments per kilo base of transcript sequence per million base pairs (FPKM) sequenced to represent the gene expression abundance. For subsequent analysis, fold change was used in analysis of measuring change in expression level of a gene.

\subsection{Quantitative Real-Time PCR Assay}

Total RNA was extracted from 200 S. coeruleus cells per sample using the RNA kit (Omega, Irving, TX, USA), following the manufacturer's instructions. After purification, RNA was treated with RNase-free DNase (Qiagen, Düsseldorf, Germany), re-purified, primed with oligo-dT, and reverse transcribed using the M-MLV Reverse Transcriptase Assay (Invitrogen, Carlsbad, CA, USA). Gene-specific primer pairs were designed for $18 \mathrm{~S}$ SSU rRNA and SCSG1 using Primer Premier 5.0 software (Table S3), and all reactions were performed on a CFX96 Real-Time System (Bio-Rad, Richmond, CA, USA) with three technical replicates. Each reaction was performed in a total volume of $20 \mu \mathrm{L}$, including $2 \mu \mathrm{L}$ cDNA, $1 \mu \mathrm{M}$ each primer, and $10 \mu \mathrm{L} 2 \times$ AceQ qPCR SYBR Green Master Mix (Vazyme, Nanjing, China). Amplification conditions were $95^{\circ} \mathrm{C}$ for $5 \mathrm{~min}$, followed by 40 cycles of $95^{\circ} \mathrm{C}$ for $10 \mathrm{~s}$ and $60^{\circ} \mathrm{C}$ for $30 \mathrm{~s}$, and then melt curve readings were obtained from $65^{\circ} \mathrm{C}$ to $95^{\circ} \mathrm{C}$, in increments of $0.5^{\circ} \mathrm{C} / 0.05 \mathrm{~s}$. All data were compared using the homogenization method.

\subsection{Induction of $O A$ Regeneration}

S. coeruleus cells in the experimental and control groups were collected by mouth pipette using a Zeiss anatomical lens (Carl Zeiss AG, Oberkochen, Germany). To induce 
OA regeneration, cells were incubated for $1 \mathrm{~min}$ in a $4 \%$ urea solution [3]. This treatment caused the MBs to be sloughed from the cells, followed by replacement of the entire complement of feeding organelles. After urea treatment, cells were washed twice in cold MSM and resuspended in fresh MSM. Somatic cells (without OA) with good morphology were picked and grown under normal culture conditions for OA regeneration [5].

\subsection{Cell Shape Imaging and Analysis}

Cell shape were preliminarily observed using a Stemi 2000C anatomical lens (Carl Zeiss AG, Oberkochen, Germany). Brightfield images were collected on a BX51 microscope equipped with $4 \times 0.13 \mathrm{NA}, 10 \times 0.3 \mathrm{NA}, 20 \times 0.5 \mathrm{NA}, 40 \times 0.75 \mathrm{NA}$, and $100 \times$ oil $1.3 \mathrm{NA}$ objectives lenses (Olympus, Osaka, Japan). Brightfield Images were captured using an DP73 digital microscope camera (Olympus, Osaka, Japan) and analyzed using cellSens imaging software version 1.16. Fluorescence images were collected on an Axio Imager A2 microscope equipped with $5 \times 0.16 \mathrm{NA}, 10 \times 0.3 \mathrm{NA}, 20 \times 0.5 \mathrm{NA}, 40 \times 0.95 \mathrm{NA}, 63 \times$ oil $1.25 \mathrm{NA}$ and $100 \times$ oil $1.3 \mathrm{NA}$ objectives lenses (Carl Zeiss AG, Oberkochen, Germany). Fluorescence images were captured using a pco.edge 4.2LT sCMOS camera (PCO AG, Kelheim, Germany) and analyzed using Zen 2.3 (blue edition).

Cell shape in control and RNAi cells were compared as follows: for each cell, the widest part of the cell outline was assumed to represent the OA, and the part farthest away from the OA was assumed to represent the holdfast [11]. The size of the cell was defined as the distance between the OA and the holdfast and calculated using the scale bars of the imaging software. Live, fully extended cells were used as controls for cell shape.

\section{Results and Discussion}

\subsection{Structure of the $\mathrm{PSCT} 3 \mathrm{C}$ RNAi Expression Vector}

The 8605 bp pSCT3C plasmid (Figure 1) was assembled via a multiple-step cloning procedure and contains three essential elements: (1) the pSCTGA-backbone (7300 bp), carrying the origin for vegetative replication, the Mob genes [24], and a $\mathrm{Km}$ resistance gene for selection; (2) two $c p c B$ promoters for expressing dsRNA of the exogenous gene; and (3) a MCS for inserting the DNA coding sequence of the target gene. We used the $E$. coli DH10B strain to replicate and transfer a pSCT3C plasmid containing the target gene sequence. Successful replication of the pSCT3C plasmid in E. coli DH10B was confirmed by PCR and sequencing.

\subsection{Synechocystis 6803 Transformation and Gene Expression Analysis}

For both Mob1 and SCSG1, three expression plasmids were constructed (to express three different regions of each gene): Mob1633, Mob1 317 , and Mob1 347 ; and SCSG1 $1_{597}$, SCSG1 $_{299}$, and SCSG1 298 plasmid (Table 1). The empty pSCT3C plasmid without any exogenous gene was used as the control. Each plasmid was introduced into Synechocystis 6803 and successful transformation was verified by bacterial colony PCR using the primer pairs listed in Table S2. The WT strain was used as the control. PCR products of the expected sizes were obtained from the Mob1 633, Mob $_{317}$, Mob1 $_{347}$, SCSG1$_{597}$, SCSG1 $_{299}$, and SCSG1 298 transformants (Figure 2A,B). As expected, a transformant carrying the empty pSCT3C plasmid (primer pair $\mathrm{FP}_{c p c B}-\mathrm{F}+\mathrm{RP}_{c p c B}-\mathrm{R}$ ) generated PCR products of $1305 \mathrm{bp}$ (Figure 2C). For WT untransformed control cells, no PCR products were obtained. We successfully transformed Synechocystis 6803 cells with Mob1 and SCSG1 gene fragments (shown in Figure 2A-C). This result also suggests that the pSCT3C RNAi expression vector can replicate in Synechocystis 6803. 


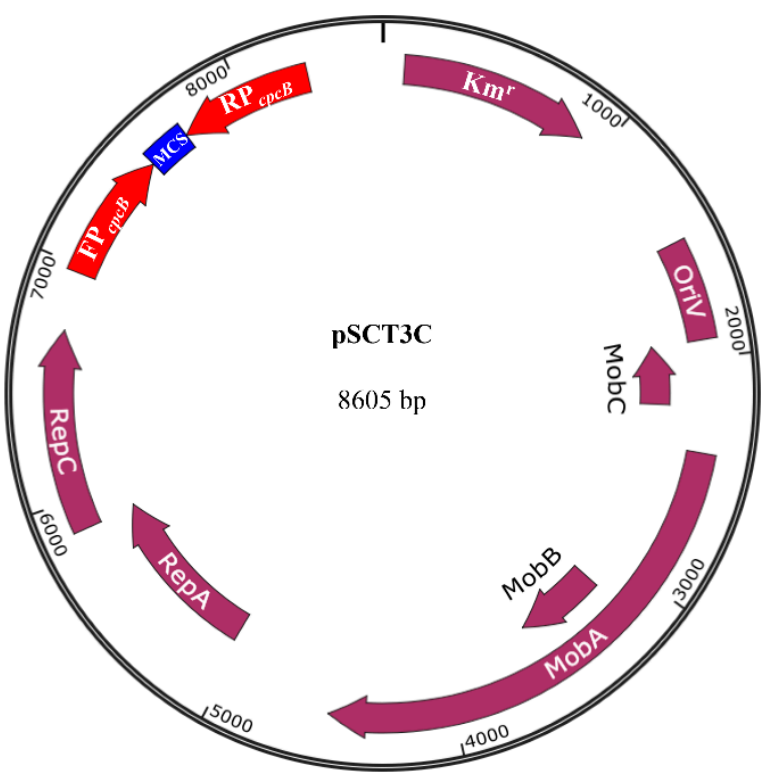

Figure 1. pSCT3C vector map. A DNA fragment of the target gene was amplified and cloned into the pSCT3C double- $\mathrm{P}_{c p c B}$ vector, which has two $c p c B$ promoters in opposite orientations flanking the multiple cloning site. The pSCT3C vector consists of the mobilization genes required for conjugative transfer and the origin for vegetative replication. The pSCT3C vector also has a selectable marker that confers $\mathrm{Km}$ resistance. Cloned plasmids are transformed into DH10B, an E. coli strain which can transfer exogenous DNA into Synechocystis PCC6803 via bacterial conjugation.

Table 1. Efficiency of RNAi constructs targeted different regions of each gene in this study.

\begin{tabular}{cccccc}
\hline Gene & Construct Name & Length (bp) & $\begin{array}{c}\text { Target Region } \\
\text { in CDS }\end{array}$ & $\begin{array}{c}\text { Sample Size } \\
\text { (Cell Number) }\end{array}$ & RNAi Efficiency \\
\hline Mob1 & Mob1 $_{633}$ & 633 & $40-672 \mathrm{bp}$ & 51 & $5.9 \%$ \\
CDS length: $675 \mathrm{bp}$ & Mob1 $_{317}$ & 317 & $40-356 \mathrm{bp}$ & 34 & $5.9 \%$ \\
& Mob1 $_{347}$ & 347 & $326-672 \mathrm{bp}$ & 40 & 0 \\
SCSG1 & SCSG1 $_{597}$ & 597 & $1-597 \mathrm{bp}$ & 53 & 58 \\
CDS length: $597 \mathrm{bp}$ & SCSG1 $_{299}$ & 299 & $1-299 \mathrm{bp}$ & 57 & 0 \\
\hline
\end{tabular}

To determine the expression of Mob1 and SCSG1 in the transformants, we analyzed the transcription of Mob1 and SCSG1 gene by RT-PCR. DNA fragments of the expected sizes were amplified in Mob1 and SCSG1 transformants and not in the WT control (Figure 2D,E). This result confirms that the Mob1 and SCSG1 gene can be expressed in Synechocystis 6803.

\subsection{Successful Knockdown of Mob1 Supports the Applicability of RNAi by Synechocystis 6803 Feeding}

To determine whether transformed Synechocystis 6803 can mediate RNAi by feeding in S. coeruleus, we first checked whether Synechocystis 6803 cells are ingested by S. coeruleus. We found that many food vacuoles in S. coeruleus cells contained the Synechocystis 6803 cells (Figure 3), suggesting that Synechocystis 6803 could be a good food resource and can be used as RNAi system at least in Stentor. 
A

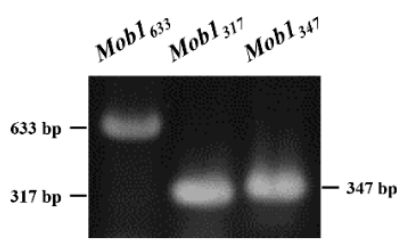

B

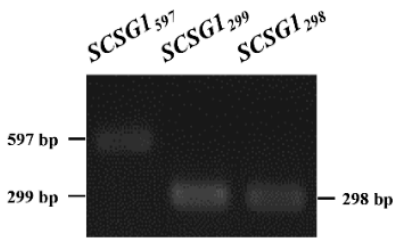

C

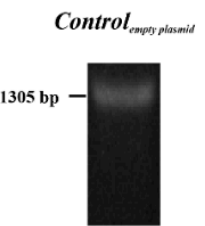

D

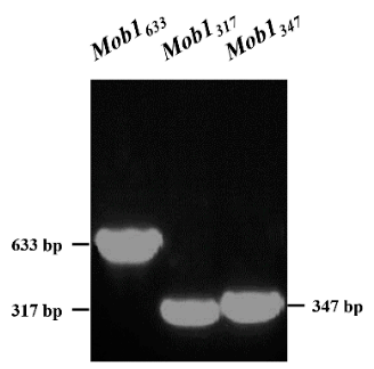

E

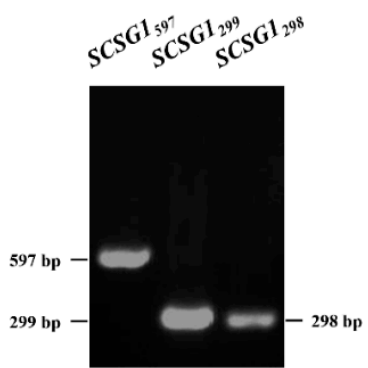

Figure 2. Verification of plasmid transformation into Synechocystis PCC6803 by bacterial colony PCR and of exogenous SCSG1 and Mob1 gene expression in Synechocystis PCC6803 transformants using RT-PCR. No DNA fragments were amplified in all controls (data not shown). (A) Bacterial colony PCR of Mob1 transformants generated DNA fragments of the expected sizes ( $633 \mathrm{bp}, 317 \mathrm{bp}$, and $347 \mathrm{bp}$, respectively). (B) Bacterial colony PCR of SCSG1 transformants generated DNA fragments of the expected sizes (597 bp, 299 bp, and 298 bp, respectively). (C) Bacterial colony PCR of a negative control transformant carrying the empty pSCT3C plasmid showed the $1305 \mathrm{bp}$ DNA fragment. (D) RT-PCR of Mob1 transformants showed DNA fragments of the expected sizes ( $633 \mathrm{bp}, 317 \mathrm{bp}$, and $347 \mathrm{bp}$, respectively). (E) RT-PCR of SCSG1 transformants showed DNA fragments of the expected sizes (597 bp, 299 bp, and 298 bp, respectively).
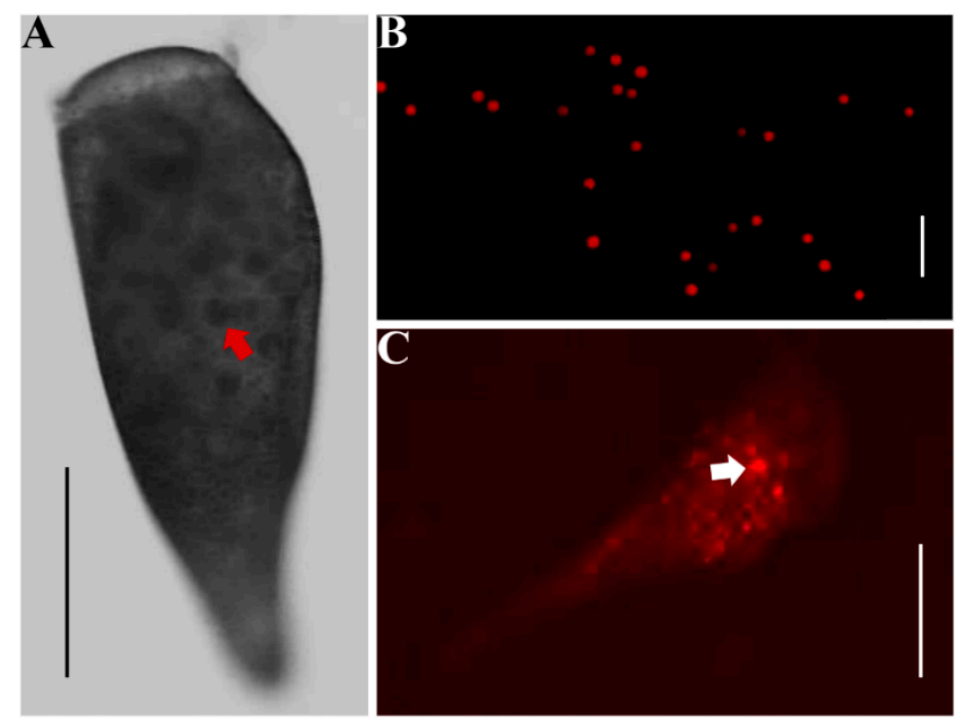

Figure 3. Ingestion of Synechocystis PCC6803 by S. coeruleus. (A) Brightfield microscopy image of a live S. coeruleus cell with Synechocystis PCC6803 stored in its food vacuoles. The red arrow indicates a food vacuole. Scale bar: $100 \mu \mathrm{m}$. (B) Autofluorescence microscopy image of live Synechocystis PCC6803 cells. Scale bar: $50 \mu \mathrm{m}$. (C) Autofluorescence microscopy image of a live S. coeruleus cell with Synechocystis PCC6803 stored in its food vacuoles. The white arrow indicates a food vacuole. Scale bar: $100 \mu \mathrm{m}$. 
To further test the applicability of our method, we next checked whether RNAi of Mob1 by Synechocystis 6803 works in S. coeruleus. Mob1 encodes a patterning protein required for Stentor morphogenesis. In a previous study, the Mob1 was knocked down using the E. coli HT115 method and the phenotypes were determined [11]. Therefore, we performed Mob1 RNAi in S. coeruleus by Synechocystis 6803 feeding. As Mob1 plays a key role in defining polarity and regulating polarized cell growth during both normal development and regeneration [11], we expected to observe phenotypes related to cell polarity. Compared with WT S. coeruleus cells under normal growth conditions (Figure 4A), Mob1 RNAi led to an aberrant cell shape after 10 days of feeding with Synechocystis 6803 including the Mob1 $1_{317}$ RNAi vector (Table 1) that included defective OA morphogenesis, loss of the characteristic "trumpet" shape, and two ectopic posterior poles (Figure 4B). After 14 days of RNAi feeding with Synechocystis 6803 including the Mob1 ${ }_{633}$ RNAi vector (Table 1), the similar phenotypes were observed in OA regeneration of Stentor, except that only one ectopic posterior pole could be seen (Figure 4C). As a result, the Mob1 RNAi efficiency is approximately $5.9 \%$ in the $M_{0 b} 1_{317}$ and $M o b 1_{633}$ RNAi cells, while we did not observe the Mob1 RNAi phenotype shown in the Mob1 ${ }_{347}$ RNAi cells (Table 1). In previously reported in another $S$. coeruleus strain, $10 \%$ of cells failed to reestablish normal cell proportions after regenerating OA/holdfast in Mob1 RNAi cells fed with E. coli HT115 [11]. Although our RNAi efficiency are less than the previous one, the Mob1 RNAi phenotypes are similar to those of the previous reports [11]. It is suggested that our RNAi method is reliable.
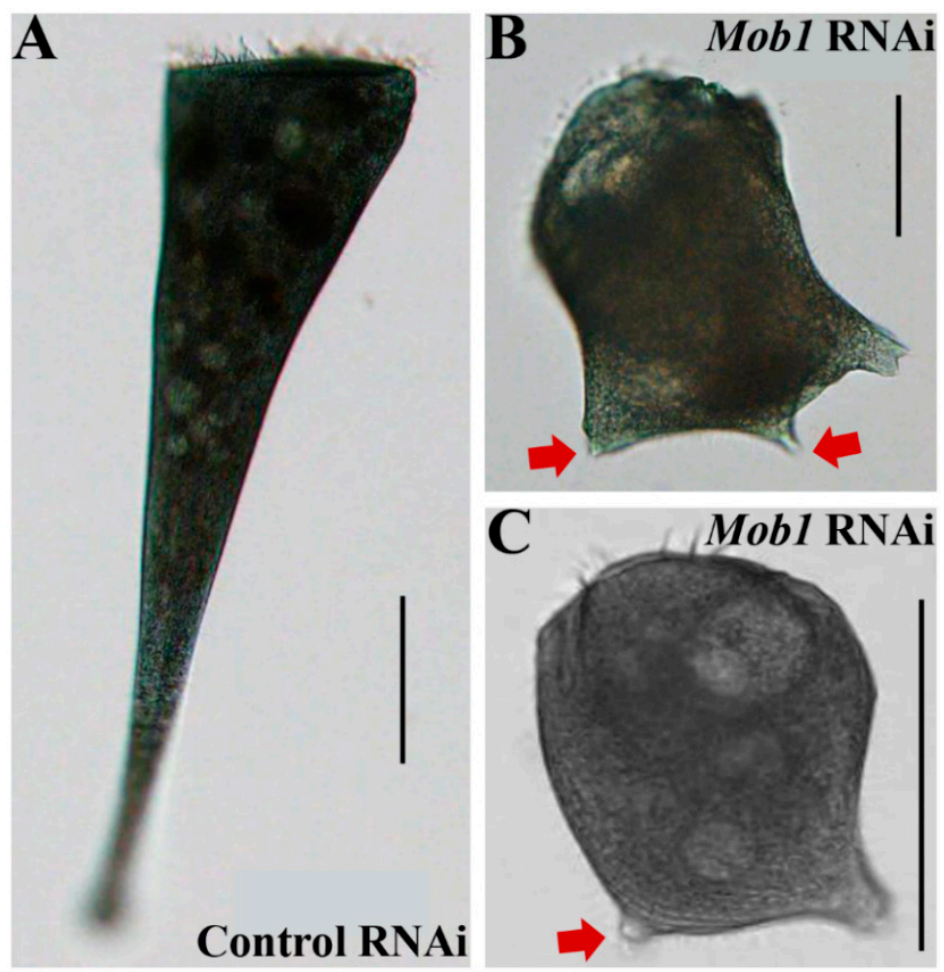

Figure 4. Mob1 RNAi resulted in aberrant cell polarity in S. coeruleus. (A,B) Representative brightfield microscopy images of cells treated with control RNAi (A) and Mob1 RNAi (B) by Synechocystis 6803 feeding for 10 days. Mob1 RNAi resulted in the development of two ectopic posterior poles (red arrows) in cell under normal growth conditions. Scale bars: $100 \mu \mathrm{m}$ (A) and $50 \mu \mathrm{m}$ (B). (C) Representative brightfield microscopy image of a cell treated with Mob1 RNAi by Synechocystis 6803 feeding for 14 days. Mob1 RNAi resulted in the development of an ectopic posterior pole (red arrow) during OA regeneration. Scale bars: $100 \mu \mathrm{m}$. 


\subsection{Gene Expression Profiles and Function Analysis of SCSG1 during OA Regeneration}

In previous single-cell RNA-seq study, we obtained 3223 upregulated differentially expressed genes (DEGs) during OA regeneration in S. coeruleus WHEL [5]. Among them, expression of 532 DEGs peaked at $3 \mathrm{~h}$, the time of OA cilia appearance. The $532 \mathrm{DEGs}$ were clustered into 50 profiles using STEM [27] (Figure 5A), and genes were significantly enriched in five profiles (No. 21, 24, 45, 37, and 13) (Figure 5A). The profile No. 45 (51 genes) shows high expression level at $3-4 \mathrm{~h}$, the very important stage of ciliogenesis in OA regeneration (Figure 5B). Therefore, we focused on these 51 genes, and found these genes including centrins, kinesins, and protein kinases which may involve in cilia growth, indicating the important functions of these genes during ciliogenesis. In these genes, we identified a highly expressed gene (SCOERU2802901, Figure 5C) which do not have any homolog in other ciliates, and thus named as S. coeruleus-specific gene (SCSG1).

A

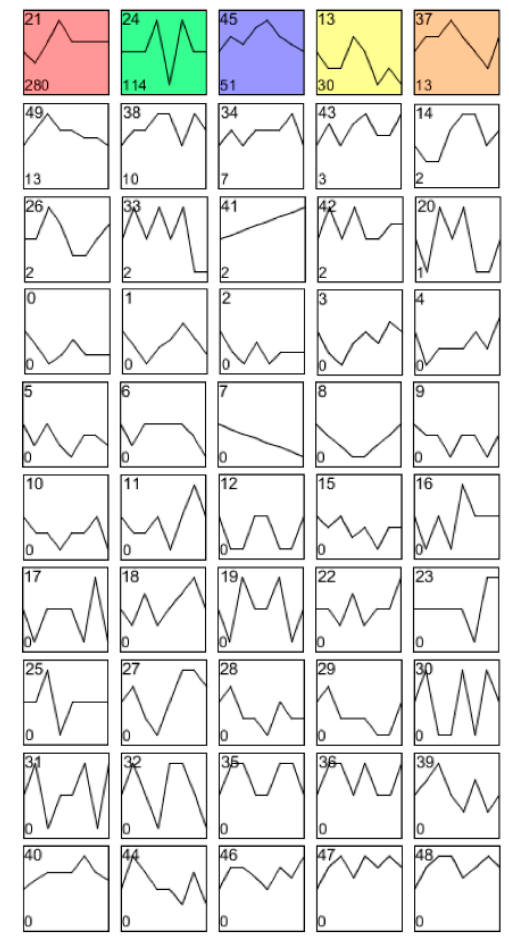

B

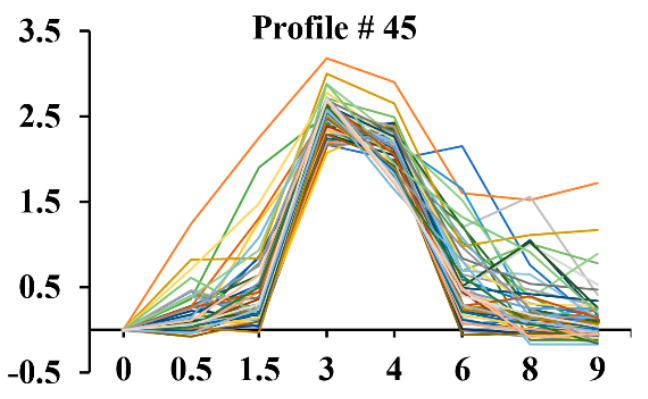

C

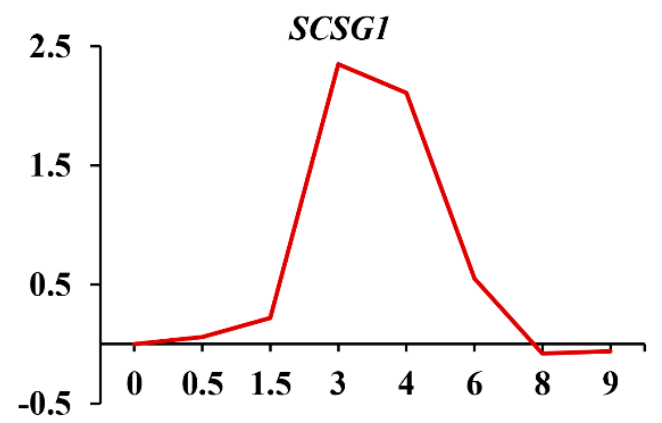

Figure 5. (A) The clustering analysis of 532 upregulated DEGs with maximum expression at the stage of the first OA cilia appearance during OA regeneration in S. coeruleus. Five expression patterns (No. 21, 24, 45, 37, and 13) of genes showed statistically significant difference $(p<0.00001)$ (colored boxes). (B) The time-series analysis of 51 upregulated DEGs in No. 45 pattern. The $x$-axis shows the time points, and the y-axis shows the time series of gene expression levels. (C) Gene expression profiles of SCSG1 gene during OA regeneration in S. coeruleus. The x-axis shows the time points, and the y-axis shows the time series of gene expression levels.

\subsection{SCSG1 RNAi Illustrates Its Essential Function in OA Regeneration}

Considering the high expression level of SCSG1 in cilia growth, we expect a phenotype that would affect the new OA formation. Therefore, we created RNAi vectors targeting various SCSG1 sequences to determine gene function. After feeding with Synechocystis 6803 for 14 days, we measured SCSG1 expression using both single-cell RNA-seq and quantitative real-time PCR (qRT-PCR). For single-cell RNA-seq, we subjected approximately 300 cells with normal morphology to urea treatment and then observed the morphology of cells every $1 \mathrm{~h}$ until OA regeneration was complete. Before urea treatment, a single cell was randomly collected to serve as a negative control for RNA-seq for baseline SCSG1 expression. For qRT-PCR analysis, we collected approximately 300 cells. The RNA-seq and qRT-PCR results showed that SCSG1 expression in S. coeruleus was significantly knocked down 
following Synechocystis 6803 feeding (Figure 6A). After OA regeneration was induced by urea treatment, about $5.2 \%$ of SCSG1 RNAi cells fed with Synechocystis 6803 including the $\mathrm{SCSG}_{299}$ RNAi vector did not regenerate a new OA (Table 1, Figure $\left.6 \mathrm{~B}, \mathrm{C}\right)$. The time course of morphological changes during OA regeneration in SCSG1 RNAi cells shown in Figure S1. These cells did not form OA cilia and adopted an aberrant shape consistent with wound healing. After a few days, cells that failed to regenerate an OA died because they could not ingest food. However, we did not observe phenotype in the SCSG1 597 and SCSG1 298 RNAi cells (Table 1). These results demonstrated that SCSG1 is required for ciliogenesis during OA regeneration in S. coeruleus. Cilia/flagella-associated protein 20 (CFAP20) was identified in the OA proteome of S. coeruleus [5]. It is a cilium/flagellum-specific protein involved in axonemal structure organization and motility in Paramecium [28] and Chlamydomonas [29], and regulates cilia size and morphology in Drosophila [30]. Notably, the expression pattern of CFAP20 is similar to the SCSG1 transcription pattern during $\mathrm{OA}$ regeneration in $S$. coeruleus we previously determined by single-cell transcriptome analysis [5], with both peaks of expression at the first appearance of OA cilia. However, SCSG1 was not found in the OA proteome of S. coeruleus. Moreover, SCSG1 RNAi did not result in defective morphogenesis during normal growth. This further suggests that SCSG1 may be a cilium-specific gene that is induced by OA regeneration and regulates cilia growth during $\mathrm{OA}$ regeneration in $S$. coeruleus.

A
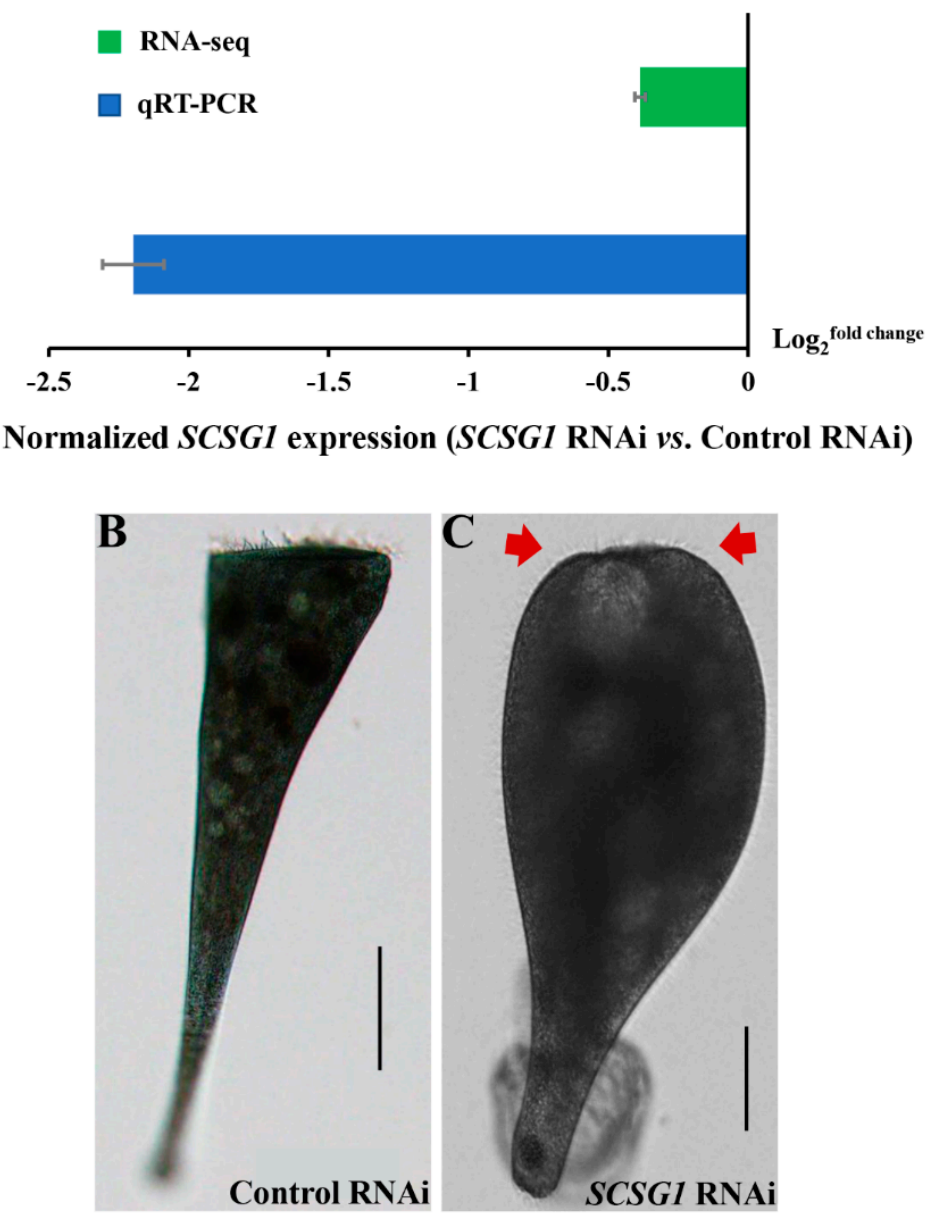

Figure 6. SCSG1 RNAi resulted in aberrant cell morphology during OA regeneration in S. coeruleus. (A) RNA-seq and qRT-PCR data showing down-regulated expression of SCSG1 normalized to $18 S$ expression in control and SCSG1 RNAi cells, respectively. (B,C) Brightfield microscopy images of S. coeruleus cells treated with control and SCSG1 RNAi, showing normal (B) and aberrant (C) cell morphology without regenerated OA (red arrows). Scale bars: $100 \mu \mathrm{m}$ (B) and $50 \mu \mathrm{m}$ (C). 
In summary, we developed a novel RNAi method in Stentor that may be applicable to other ciliates that can use cyanobacteria as food. Using the new RNAi method, we confirmed that SCSG1 has an essential function in ciliogenesis during OA regeneration in S. coeruleus.

Supplementary Materials: The following are available online at https:/ /www.mdpi.com/2076-260 7/9/1/176/s1. Figure S1: Selected images from a time course of morphological changes in control and SCSG1 RNAi cells during OA regeneration in S. coeruleus. Control and SCSG1 RNAi cells were observed after the start of OA regeneration and imaged every $2 \mathrm{~h}$. (A,B) Brightfield microscopy images of S. coeruleus cells treated with control and SCSG1 RNAi, showing normal cell morphology of OA regeneration (A) (black arrows) and aberrant cell morphology without regenerated OA (B) (red arrows). Scale bars: $100 \mu \mathrm{m}$ (A) and $50 \mu \mathrm{m}$ (B). Table S1: Primers with specific adaptor sequences information for the PCR amplify with homologous recombination method; Table S2: Information of RNAi constructs in this study. Their lengths and relative positions within the coding sequence, and primers with restriction enzyme cutting site and protective base used to amplify the sequences from genomic samples; Table S3: Primers used for qRT-PCR analysis.

Author Contributions: Conceptualization, W.M., J.X., and W.W.; methodology, W.W., C.J., X.C., J.Z., C.-C.Z., and W.M.; formal analysis, W.W., C.J., and J.X.; writing-original draft preparation, W.W. and C.J.; writing-review and editing, J.X. and W.M.; supervision, J.X. and W.M.; funding acquisition, W.M., J.X., and C.J. All authors have read and agreed to the published version of the manuscript.

Funding: This work was supported by grants from National Natural Science Foundation of China to WM (21976208), JX (31872221), and CJ (31900339), the Bureau of Frontier Sciences and Education, Chinese Academy of Sciences to WM (ZDBS-LY-SM026), the China Postdoctoral Science Foundation to CJ (2018M642954), the Natural Science Foundation of Hubei Province to JX (2019CFB808) and the Youth Innovation Promotion Association of the Chinese Academy of Sciences to JX.

Data Availability Statement: The sequencing data is freely available at http://bigd.big.ac.cn/gsa/ s/J4yTU1HH.

Conflicts of Interest: The authors declare that they have no conflict of interest.

\section{References}

1. Tartar, V. The Biology of Stentor; Pergammon Press: Oxford, UK, 1961.

2. Neviackas, J.A.; Margulis, L. The effect of colchicine on regenerating membranellar cilia in Stentor coeruleus. J. Protozool. 1969, 16, 165-171. [CrossRef]

3. Tartar, V. Reactions of Stentor coeruleus to certain substances added to the medium. Exp. Cell Res. 1957, 132, 317-332. [CrossRef]

4. Sood, P.; McGillivary, R.; Marshall, W.F. The transcriptional program of regeneration in the giant single cell, Stentor coeruleus. Biorxiv Cell Biol. 2017, in press.

5. Wei, W.; Jiang, C.Q.; Yang, W.T.; Miao, W.; Xiong, J. Proteomic identification and expression of oral apparatus constituents in cell regeneration of giant ciliate Stentor coeruleus (strain WHEL). Gene 2020, 743, 144624. [CrossRef] [PubMed]

6. Galvani, A.; Sperling, L. RNA interference by feeding in Paramecium. Trends Genet. 2002, 18, 11-12. [CrossRef]

7. Möllenbeck, M.; Postberg, J.; Paeschke, K.; Rossbach, M.; Jönsson, F.; Lipps, H.J. The telomerase-associated protein p43 is involved in anchoring telomerase in the nucleus. Cell Sci. 2003, 116, 1757-1761. [CrossRef]

8. Nowacki, M.; Vijayan, V.; Zhou, Y.; Schotanus, K.; Doak, T.G.; Landweber, L.F. RNA-mediated epigenetic programming of a genome-rearrangement pathway. Nature 2008, 451, 153-158. [CrossRef]

9. Heyse, G.; Jönsson, F.; Chang, W.J.; Lipps, H.J. RNA-dependent control of gene amplification. Proc. Natl. Acad. Sci. USA 2010, 107, 22134-22139. [CrossRef]

10. Kamath, R.S.; Martinez-Campos, M.; Zipperlen, P.; Fraser, A.G.; Ahringer, J. Effectiveness of specific RNA-mediated interference through ingested double-stranded RNA in Caenorhabditis elegans. Genome Biol. 2001, 2, 2.

11. Slabodnick, M.M.; Ruby, J.G.; Dunn, J.G.; Feldman, J.L.; DeRisi, J.L.; Marshall, W.F. The kinase regulator Mob1 acts as a patterning protein for Stentor morphogenesis. PLoS Biol. 2014, 12, 1-12. [CrossRef]

12. Konior, K. Tale of Two Proteins Sfi1p-Like and Centrin: Modeling of Contraction and Relaxation in V. convallaria. Ph.D. Thesis, University of Illinois at Chicago, Chicago, IL, USA, 2013.

13. Yu, Y.; You, L.; Liu, D.; Hollinshead, W.; Zhang, F.Z. Development of Synechocystis sp. PCC 6803 as a phototrophic cell factory. Mar. Drugs 2013, 11, 2894-2916. [CrossRef] [PubMed]

14. Kaneko, T.; Sato, S.; Kotani, H.; Tanaka, A.; Asamizu, E.; Nakamura, Y.; Miyajima, N.; Hirosawa, M.; Sugiura, M.; Sasamoto, S.; et al. Sequence analysis of the genome of the unicellular cyanobacterium Synechocystis sp. strain PCC6803. II. sequence determination of the entire genome and assignment of potential protein-coding regions. DNA Res. 1996, 3, 109-136. [CrossRef] 
15. Marraccini, P.; Bulteau, S.; Cassier-Chauvat, C.; Mermet-Bouvier, P.; Chauvat, F. A conjugative plasmid vector for promoter analysis in several cyanobacteria of the genera Synechococcus and Synechocystis. Plant Mol. Biol. 1993, 23, 905-909. [CrossRef]

16. Durfee, T.; Nelson, R.; Baldwin, S.; Plunkett, G.; Burland, V.; Mau, B.; Petrosino, J.F.; Qin, X.; Muzny, D.M.; Ayele, M.; et al. The complete genome sequence of Escherichia coli DH10B: Insights into the biology of a laboratory workhorse. Bacteriology 2008, 190, 2597-2606. [CrossRef] [PubMed]

17. Varman, A.M.; Xiao, Y.; Pakrasi, H.B.; Tang, Y.J. Metabolic engineering of Synechocystis sp. strain PCC 6803 for isobutanol production. Appl. Environ. Microbiol. 2013, 79, 908-914. [CrossRef]

18. Elhai, J.; Vepritskiy, A.; Muro-Pastor, A.M.; Flores, E.; Wolk, C.P. Reduction of conjugal transfer efficiency by three restriction activities of Anabaena sp. strain PCC 7120. Bacteriology 1997, 179, 1998-2005. [CrossRef] [PubMed]

19. Heidorn, T.; Camsund, D.; Huang, H.H.; Lindberg, P.; Oliveira, P.; Stensjö, K.; Lindblad, P. Synthetic biology in cyanobacteria: Engineering and analyzing novel functions. Methods Enzymol. 2011, 497, 539-579. [PubMed]

20. Imashimizu, M.; Fujiwara, S.; Tanigawa, R.; Tanaka, K.; Hirokawa, T.; Nakajima, Y.; Higo, J.; Tsuzuki, M. Thymine at -5 is crucial for cpc promoter activity of Synechocystis sp. strain PCC 6714. Bacteriology 2003, 185, 6477-6480. [CrossRef] [PubMed]

21. Jeamton, W.; Dulsawat, S.; Laoteng, K.; Tanticharoen, M.; Cheevadhanarak, S. Phycocyanin promoter of Spirulina platensis controlling heterologous expression in cyanobacteria. J. Appl. Phycol. 2011, 23, 83-88. [CrossRef]

22. Zhou, J.; Zhang, H.F.; Meng, H.K.; Zhu, Y.; Bao, G.H.; Zhang, Y.P.; Li, Y.; Ma, Y.H. Discovery of a super-strong promoter enables efficient production of heterologous proteins in cyanobacteria. Sci. Rep. 2014, 4, 4500. [CrossRef]

23. Elhai, J.; Wolk, C.P. Conjugal transfer of DNA to cyanobacteria. Methods Enzymol. 1988, 167, 747-754. [PubMed]

24. Scholz, P.; Haring, V.; Wittmann-Liebold, B.; Ashman, K.; Bagdasarian, M.; Scherzinger, E. Complete nucleotide sequence and gene organization of the broad-host-range plasmid RSF1010. Gene 1989, 75, 271-288. [CrossRef]

25. Slabodnick, M.M.; Ruby, J.G.; Reiff, S.B.; Swart, E.C.; Gosai, S.; Prabakaran, S.; Witkowska, E.; Larue, G.E.; Fisher, S.; Freeman, R.M.; et al. The macronuclear genome of Stentor coeruleus reveals tiny introns in a giant cell. Curr. Biol. 2017, 27, 569-575. [CrossRef] [PubMed]

26. Grabherr, M.G.; Haas, B.J.; Yassour, M.; Levin, J.Z.; Thompson, D.A.; Amit, I.; Adiconis, X.; Fan, L.; Raychowdhury, R.; Zeng, Q.D.; et al. Full-length transcriptome assembly from RNA-Seq data without a reference genome. Nat. Biotechnol. 2011, $29,644-652$. [CrossRef] [PubMed]

27. Ernst, J.; Bar-Joseph, Z. STEM: A tool for the analysis of short time series gene expression data. BMC Bioinform. 2006, 7, 191. [CrossRef] [PubMed]

28. Laligne, C.; Klotz, C.; Loubresse, N.G.; Lemullois, M.; Hori, M.; Laurent, F.X.; Papon, J.F.; Louis, B.; Cohen, J.; Koll, F. Bug22p, a conserved centrosomal/ciliary protein also present in higher plants, is required for an effective ciliary stroke in Paramecium. Eukaryot. Cell 2010, 9, 645-655. [CrossRef]

29. Yanagisawa, H.A.; Mathis, G.; Oda, T.; Hirono, M.; Richey, E.A.; Ishikawa, H.; Marshall, W.F.; Kikkawa, M.; Qin, H. FAP20 is an inner junction protein of doublet microtubules essential for both the planar asymmetrical waveform and stability of flagella in Chlamydomonas. Mol. Biol. Cell 2014, 25, 1472-1483. [CrossRef]

30. Maia, T.M.; Gogendeau, D.; Pennetier, C.; Janke, C.; Basto, R. Bug22 influences cilium morphology and the post-translational modification of ciliary microtubules. Biol. Open 2014, 3, 138-151. [CrossRef] 